\title{
Short And Long Term Effects Of Tourism Gdp Performance In Malaysia
}

\author{
INTAN MAIZURA ABD RASHID ${ }^{1}$ \\ UNIVERSITI TEKNOLOGI MARA, ALOR GAJAH, MELAKA, MALAYSIA \\ intanmaizuraar@gmail.com \\ WAN AHMAD FAUZI WAN HUSAIN ${ }^{2}$ \\ UNIVERSITI MALAYSIA PERLIS, MALAYSIA \\ SUZANA AB RAHMAN ${ }^{3}$ \\ KOLEJ UNIVERSITI ISLAM MELAKA, MALAYSIA \\ HAMIDAH NORMAN ${ }^{4}$ \\ KOLEJ UNIVERSITI ISLAM MELAKA, MALAYSIA \\ IRZA HANIE ABU SAMAH ${ }^{5}$ \\ UNIVERSITI TEKNOLOGI MALAYSIA, MALAYSIA
}

\begin{abstract}
:
This study applies observational investigation and concentrates on two primary variables which foreign direct investment and tourism. Information from 1991 to 2019 was gathered from World Bank to focus the relationship among the variables. The tests used to decipher this result are Stationary Test, Co-integration Test, Vector Error Correction Model and Granger Causality test. First, the Stationary Test focused on the Augmented Dickey Fuller $(A D F)$ test was measuring about the time series data's stationary property. Next, the method used to assess the existence of the relationship between two foreign direct investment variables and tourism is the Co-integrated Test. The Vector Error Correction Model (VECM) includes a bug fix model that should focus on the core behavior of that model. VECM specifies a simulated model that changes simultaneously towards its long-term estimates. It shows that disequilibrium disease will join in to make it work longer. VECM similarly observed the relationship between the variables over time. Finally, the Granger Causality Test was performed to look at the causal relationship between the two variables which is the relationship between foreign direct investment and tourism.
\end{abstract}

Keywords:Short term analysis, Long term analysis, Tourism, Panel data, Malaysia.

\section{INTRODUCTION}

In Malaysia, tourism sector are been improved to encourage more foreign investors to invest in our country. Besides improving the tourism sector, Malaysia government provides some initiatives and tax exclusion to encourage foreign investors invest in Malaysia. Even though many countries have made a significant improvement in their competitiveness, employment, standard of living and the production productivity, but the impact of foreign direct investment should be different to each country. Some researchers argued that foreign direct investment can encourage technology transfer and knowledge spillover from foreign to domestic country as well as promoting employment in recipient countries. There is no reasonable proof about the net effect of foreign direct investment on Malaysia's investment development. This study will manage issue by analyzing the effect of foreign direct investment of tourism sector in Malaysia. 
Research Objectives: This study has been carried out with the main objective to examine the foreign direct investment (FDI) in tourism sector in Malaysia.

There are some specified objectives included in this study, those objectives are as follow:

I. To determine the long run relationship between FDI and tourism sector.

II. To examine the short run relationship between FDI and tourism sector.

\section{Hypothesis: \\ Hypothesis 1}

H0: $\quad$ There is no relationship between foreign direct investment and tourism in the long run.

H1: There is a relationship between foreign direct investment and tourism in the long run.

\section{Hypothesis 2}

H0: There is no relationship between foreign direct investment and tourism in the short run.

H1: There is a relationship between foreign direct investment and tourism in the short run.

\section{METHODOLOGY}

There are some studies done on relationship between foreign direct investment and tourism sector. Each of the study has distinctive methodology or system that has been used to measuring the causality relationship. In this chapter will be present the econometric method that applied in this study. This part is separated into two areas which is the examination plan and exploration approach. Area one, are examines about the information portrayal and model of exploration, while the second segment talks about the examination technique of the study including the models connected in this research such as Unit Root Tests, co-integration Test, Granger Causality, to examine the causality relationship among foreign direct investment and tourism.collection is any procedure of get ready and gathering information. The reason for information accumulation is to analyze and obtain information to settle on choices about important issues, or to pass information on to others. Data that has been used is a secondary data that provide information regarding the relationship among foreign direct investment and tourismData.Data can be found in internet or can get at the library and from the economic report. All the data and information are collected from Malaysia index mundi, World Bank and Economic report.In finishing this study, the examples that have been utilized are focused around 29 years information in yearly premise. The data collected is the monthly data. The data that has been collected were foreign direct investment and tourism which is the variable of this research. The research is measure the relationship between foreign direct investment and tourism sector. The tourism sector is the independent variable and the foreign direct investment is dependent variable. The entire variable is in term of Ringgit Malaysia (RM).

\section{METHOD OF ANALYSIS}

For this study, Econometric Views (EVIEWS) is utilized to break down all the information gathering and decipher the result discoveries. The crude information gathered in the field must be converted into data that will address the exploration addresses with a specific end goal to distinguish the relationship between foreign direct investment and tourism sector.

Statistical Method Analysis 
The current study utilizes Vector Error Correction Model (VECM) dissection to test the presence of the Phillips curve in Malaysia for the period from 1991 to 2019. Three different econometric routines are utilized as a part of this exploration, i.e., 1) unit root test, 2) Johansen cointegration test, and 3) Granger causality focused around the VECM. The basic Phillips curve could be assessed by utilizing succeeding equation:

$F D I t=\alpha 0+\beta 1 T t-1+\varepsilon t$

$T=\alpha 0+\beta 1 F D I t-1+\varepsilon t$

Where $\alpha 0$ is steady and $\boldsymbol{\beta} 1$ is slop coefficient. FDItis outside immediate financing in Malaysia in the yeart,Ttis the tourism in Malaysia in the yeartandetis the lapse term then again, fusing characteristic rate of tourism into the model, the "standard" Phillips bend could be communicated.

$$
\begin{gathered}
\text { FDIt }=\alpha(L) F D I t-1+\beta(L)(T t-N T t)+\varepsilon t \\
T t=\alpha(L) T t-1+\beta(L)(F D I t-F D I t)+\varepsilon t
\end{gathered}
$$

Where $\boldsymbol{\alpha}(\mathbf{L})$ and $\boldsymbol{\beta}(\mathbf{L})$ are polynomials in the slack operation, NTtis common rate of tourism or NAIRT (non-accelerating rate of tourism) in Malaysia in the yeart. The vast majority of the current hypothetical and observational written works have been focused around the equation 2. The equation could be altered as:

$$
\begin{aligned}
& F D I t=\alpha(L) F D I t-1+\beta(L) T G t+\varepsilon t \\
& T t=\alpha(L) T t-1+\beta(L) F D I G t+\varepsilon t
\end{aligned}
$$

WhereTGtis the "tourism gap" (i.e. the genuine tourism short regular rate of tourism). Help for the Phillips curve would oblige negative and noteworthy coefficients for the tourism gap. The observational investigation will be focused on the equation 3 .

\section{Unit Root Test}

The main business of developing time series knowledge is to focus on non-stationary assets. We should examine each series in the first levels and differences. All variables were tested at levels using the Augmented Dickey-Fuller (ADF) Test. Consider the following figure:

$$
\Delta Y_{t}=\beta_{1}+\beta_{2} t+\delta Y_{t-1}+\alpha \sum_{i=1}^{p} \Delta Y_{t-1}+u_{t}
$$

where our investment flexibility, is the time frame with the divider control, it is the time method, $\mathrm{P}$ is the reduced time value and with the mean background zero mean and the mean mean and constant variance. $(\alpha 1, \alpha 2, \beta 1, \ldots \beta \mathrm{m})$ is obtained by parameters to be tested. When the test probability is noticeable, the variable configuration stops and has no unit root. In this way, the invalid theory will be rejected, but the speculation of choice will be accepted. However, if a standing test is not necessary, the flexible configuration is not fixed and has a unit root; hence, invalid comment will be accepted. The opinion of this study is as follows:

$$
\begin{aligned}
& H_{0}: \delta=0 \text { (unit root/ non stationary) } \\
& H_{1}: \delta \neq 0 \text { (no unit root/ stationary) }
\end{aligned}
$$




\section{Granger Causality Test}

The Granger causality test is utilized to analyse the causal relationship between two variables. In the event that the $\mathrm{p}$ values of the variable $\mathrm{Y}$ essentially help estimate the worth of an alternate variable $\mathrm{X}$, then $Y$ has a Granger causal relationship with $X$ and vice versa. The test is focused on the equation below.

$$
\begin{aligned}
& Y_{t}=\gamma_{0}+\sum_{z=1}^{p} \gamma_{z} Y_{t-z}+\sum_{i=1}^{q} \lambda_{i} X_{t-1}+\mu_{t} \\
& X_{t}=\varphi_{0}+\sum_{z=1}^{p} \delta_{z} X_{t-z}+\sum_{i=1}^{q} \Psi_{i} Y_{t-1}+\varepsilon_{t}
\end{aligned}
$$

Where Yt and Xt are experimental variables, andt and aret are the default values, and t means the time $z$ and $i$ are the number of lags. The null hypothesis is $\lambda \_i=\Psi \_i=0$ for all $i$. In another hypothesis $\lambda \_i \neq 0$ and $\Psi_{-} i \neq 0$ at least some $i$ 's if the coefficient $\lambda_{-} i$ is important but $\Psi_{-} \mathrm{i}$ is not important, then $\mathrm{X}$ is the cause of the Granger in Y. . This study uses exploratory research and focuses on the fundamental variables of direct foreign investment and tourism. Data from 1991 to 2019 were collected from the World Bank to focus on the relationship between the change. The tests used to determine this effect are Stationary Test, Co-integrated Test, Vector Error Correction Model and Granger Causality test. First, the Stationary Test focused on the Augmented Dickey Fuller (ADF) test measuring the fixed assets of a time series. Next, the method used to assess the existence of the relationship between two foreign direct investment variables and tourism is the Co-integrated Test. The Vector Error Correction Model (VECM) includes a bug fix model that should focus on the core behavior of that model. VECM specifies a simulated model that changes simultaneously towards its long-term estimates. It shows that disequilibrium disease will join in to make it work longer. VECM similarly observed the relationship between the variables over time. Finally, the Granger Causality Test was performed to look at the causal relationship between the two variables which is the relationship between foreign direct investment and tourism.

\section{RESULTS}

Unit Root Test is paramount in deciding the stationary properties of the time arrangement information. The test speaks to a relationship of the variables whether it is in the same request of integration. Along these lines, the examination is carried out by utilizing Augmented Dickey-fuller (ADF) Unit Root Test. To focus the stationary properties of the variables included in Malaysia which is foreign direct investment and tourism, table 1 is available the consequences of Unit Root Test of Augmented Dickey-Fuller. The results are differentiated into level and first contrast under steady and consistent with pattern.

\begin{tabular}{|c|c|c|c|c|}
\hline \multirow[b]{2}{*}{ Variable } & \multicolumn{2}{|l|}{ Intercept } & \multicolumn{2}{|c|}{ Intercept + Trend } \\
\hline & Level & \begin{tabular}{|l} 
First \\
difference
\end{tabular} & Level & $\begin{array}{l}\text { First } \\
\text { difference }\end{array}$ \\
\hline $\begin{array}{l}\text { Foreign Direct } \\
\text { Investment }\end{array}$ & $\begin{array}{l}-1.118912 \\
(0.7086)\end{array}$ & $\begin{array}{l}-11.84641 * \\
(0.00)\end{array}$ & $\begin{array}{l}-2.631637 \\
(0.2667)\end{array}$ & $\begin{array}{l}-11.82286^{*} \\
(0.00)\end{array}$ \\
\hline
\end{tabular}

Table 1 Unit Root Test Result 


\begin{tabular}{|l|l|l|l|l|}
\hline Tourism & -0.519586 & $-4.977634^{*}$ & -2.738464 & $-4.868969^{*}$ \\
& $(0.8729)$ & $(0.0004)$ & $(0.2300)$ & $(0.0030)$ \\
\hline
\end{tabular}

Note: $*, * *, * * *$ are significant respectively to $1 \%, 5 \%$ and $10 \%$

For the first variable which is the foreign direct investment, the result found under the intercept is stationary at the the first and only non-standard difference. At the levels, the probability of 0.7086 and t-statistic is 1.118912 ; while with the first difference, the probability of 0.00 and t-statistic is -1.84641 . Under the restricted trend, it is found that the grip is not up to standard and has stopped the first difference. At the level, the probability of 0.2667 and $t-$ statistic is - 2,631637; while with the first difference, the probability of 0.0000 and t-statistic is -1.82286 . The result proved to be $1 \%$ important.

The second variation which is the tourism sector, the result obtained below is not static and stands for the first difference. At the level, the probability of 0.8729 and t-statistic is 0.519586; while with the first difference, the probability of 0.0004 and t-statistic is 4.977634 . Under the restricted trend, it is found that the grip is not up to standard and has stopped the first difference. At the level, the probability of 0.2300 and the t-statistic is - 2,738464; while with the first difference, the probability of 0.0030 and t-statistic is 4.868969 . The result proved to be $1 \%$ important.

\section{Lag Selection Terms}

In the second phase, the Johansen integration test was used to test the long-term development of variability. As Engle and Granger (1987) point out, the only downside to a single application for joining can be attempted to unite. All assumptions, in the present study, both variables can be tested for mergers. Above all else, the Akaike Information Criterion (AIC) has been used to focus on choosing the best lengths while the maximum length is available in three (3). Table 2 shows that the optimal length of the Johansen compound test test alone (1), which reduces AIC. Also, AIC has also been used to focus on the most appropriate model for Johansen integration testing.

Table 2Lag Selection Criteria

\begin{tabular}{|l|l|l|}
\hline Lag & AIC & SC \\
\hline $\mathbf{0}$ & 4.924148 & 5.020925 \\
\hline $\mathbf{1}$ & $2.500325^{*}$ & $2.790655^{*}$ \\
\hline $\mathbf{2}$ & 2.797970 & 3.281854 \\
\hline $\mathbf{3}$ & 2.781387 & 3.458824 \\
\hline
\end{tabular}

Note: $*, * * * * *$ are respectively significant to $1 \%, 5 \%$ and $10 \%$

Based on the table 2, the result shows that lag 1 has been selected which is the AIC value is 2.500325 that significant to 1 per cent. Johansen Cointegration is then applied. The other lag 
has a higher AIC value than Lag 1 where (lag $0=4.924148)$, (lag $2=2.797970)$, and (lag 3 $=2.781387$ ) respectively.

\section{Co-Integration Test Result}

Table 3Cointegration Test Results

\begin{tabular}{|l|l|l|l|l|}
\hline Rank & $\begin{array}{l}\text { Max-Eigen } \\
\text { Statistic }\end{array}$ & $\begin{array}{l}\text { Critical Value } \\
\text { (Eigen) at 5\% }\end{array}$ & Trace Statistic & $\begin{array}{l}\text { Critical Value } \\
\text { (Trace) at 5\% }\end{array}$ \\
\hline $\mathrm{r}=0^{*}$ & 22.99913 & 14.26460 & 23.50073 & 15.49471 \\
\hline $\mathrm{r} \leq 1$ & 0.501597 & 3.841466 & 0.501597 & 3.841466 \\
\hline
\end{tabular}

Note: L.R test indicates one co-integrating equation at the 0.05 level

Table 3 shows the results of the Co-integrated Test. Exhibits of both Maximum Eigen Statistic and Trace Statistic are present in Malaysia at a 5 percent level between the two variants. This means that direct foreign investment and tourism are combined. In the null hypothesis, the Trace Statistic for foreign direct investment is 23.50073, which is higher than Critical Value (Trace) 15.49471 at a value level of 5 percent. This Trace Statistic result has made it clear that this figure has a long-term relationship between the variance in the 5 percent value level. Subsequently, by Max-Eigen's figure, the result showed a correlation between the variance over time at the key level of $5 \%$. This is because the number of Max-Eigen figures is 22,99913 higher than the critical number (Eigen) at 14,26460 at the critical level of 5\%. Tourism is therefore linked to direct investment in other countries. Johansen's procedure can be linked to this study to determine the long-term coefficient of the model. In addition, with the Trace Statistics category $r \leq 1$, the prices are lower than the Critical (trace) quality, which exceeds the value level. At level $r$, the Trace Statistic value is 0.501597 which is less than the Critical (trace) value of 3.841466 at a value level of 5 percent. Therefore, one combination exists. In any case, the $r \leq 1$ rank of Max-Eigen Statistic, values lower than Critical Value (Eigen), also added value, as did Trace Statistic and Critical Value (Trace). At level $r \leq 1$, the Max-Eigen Statistic value is 0.501597 less than the Critical (Eigen) value of 3.841466 at a value of 5 percent.

\section{Vector Correlation Model (VECM)}

Table 4 Vector Correlation Model (VECM)

\begin{tabular}{|l|l|l|l|}
\hline DV (FDI) & Coefficient & t-statistic & Prob. \\
\hline FDI (-1) & 0.022609 & 0.108421 & 0.9146 \\
\hline Tourism(-1) & -0.549296 & -0.420037 & 0.6784 \\
\hline ECM (-1) & -0.894571 & $-3.232307^{*}$ & 0.0037 \\
\hline DV (Tourism) & Coefficient & t-statistic & Prob. \\
\hline Tourism (-1) & 0.007853 & 0.037234 & 0.9706 \\
\hline FDI (-1) & -0.007332 & -0.218006 & 0.8293 \\
\hline ECM (-1) & -0.002789 & -0.083012 & 0.9346 \\
\hline
\end{tabular}

Note:*,**,*** are significant to the $1 \%, 5 \%$, and $10 \%$ respectively

Table 4 shows the VECM test. The findings reveal that the number of short-term error correction terms (ECTi-1) is positive and statistically significant between direct foreign investment and tourism where direct foreign investment turns out to be a reliable variance. 
The equal value is negative which is a value of -0.894571 and its t-statistic is also negative where the value is $-3,232307$. The relationship was shaped which is the probability of being 0.0037 the most important at 1 percent. Therefore, it can ensure a long-term relationship between inflation and unemployment. However, it does not matter when tourism is a dependent variable, where (ECTi-1) has a negative value of 0.002789 . The t-statistic also has a negative value of -0.083012 . The relationship did not stop with the potential for 0.9346 chances.

\section{Granger Causality Test Result}

Co-integrated testing cannot be used to focus on the direction of interpersonal relationships; The Pair wise Granger Causality test is aimed at determining whether the timeline data details are subscribed or not (which are the causes between the 2 variables). Granger causality testing relationships are requested for all variables. In the case where the F-value is lower than the Fcritical, it means that there is no risk factor between the variables. Timeline details were tested prior to conducting the causality test using the Unit Root Test and the Co-integrated Test.

Table 5 Granger Causality Test Results

\begin{tabular}{|l|l|l|}
\hline Null Hypothesis: & F-Statistic & Prob. \\
\hline LNFDI does not Granger Cause LNTOURISM_A_ & 0.01752 & 0.8958 \\
\hline LNTOURISM_A_does not Granger Cause LNFDI & $4.26352 * *$ & $0.0495^{* *}$ \\
\hline
\end{tabular}

Note: $* * *$ and $* * *$ denote statistical significance at the $1 \%, 5 \%$ and $10 \%$ level, respectively.

Table 5 present the granger causality among the Foreign Direct Investment (FDI), and tourism. For the correlations between FDI and tourism, the result show that FDI does not granger cause to Tourism because $(\mathrm{P}$-value $=0.8958, \mathrm{~F}$-statistic $=0.01752)$, tourism does not granger cause to FDI $(\mathrm{P}$-value $=0.1300, \mathrm{~F}-$ Statistic $=2.05945)$.

\section{CONCLUSION}

In conclusion the result of the research conducted shows that there are relationship between the foreign direct investment and tourism. Thus the hypothesis is accepted. In this result also showed that the long run relationship occurs and also the causality between foreign direct investment and tourism.

Table 6 Result of Hypothesis in Malaysia

\begin{tabular}{|l|l|l|}
\hline Hypothesis & Statement of Hypothesis & Result \\
\hline $\mathrm{H}_{1}$ & $\begin{array}{l}\text { There are relationship between foreign direct } \\
\text { investment and tourism in the long run }\end{array}$ & Accepted \\
\hline
\end{tabular}




\begin{tabular}{|l|l|l|}
\hline $\mathrm{H}_{2}$ & $\begin{array}{l}\text { There are relationship between foreign direct } \\
\text { investment and tourism in the short run }\end{array}$ & Accepted \\
\hline
\end{tabular}

\section{References}

[1] Adam P. Balcerzak, M. Ż. (2011). Foreign Direct Investment and Unemployment: VAR Analysis for Poland in the Years 1995-2009. Foreign Direct Investment and Unemployment: VAR Analysis for Poland in the Years 1995-2009.

[2] Aigner, D. J. (1984).Latent variable models in econometrics.Latent variable models in econometrics.

[3] Aizenman, J. (2005). FDI and Trade - Two Way Linkages?FDI and Trade - Two Way Linkages?

[4] Alfaro, L. (2003). Foreign Direct Investment and Growth: Does the Sector Matter?. Foreign Direct Investment and Growth: Does the Sector Matter?

[5] Arellano, M. and Bond, S. (1991).Some Test of Specification for Panel Data: Monte Carlo Evidence and Application to Employment Equation.Some Test of Specification for Panel Data: Monte Carlo Evidence and Application to Employment Equation.

[6] Biørn, E. (1992). Econometrics of panel data with measurement errors.Econometrics of panel data with measurement errors.

[7] Buckley, P. J. (2007). The Determinants of Chinese Outward Foreign Direct Investment. The Determinants of Chinese Outward Foreign Direct Investment.

[8] licaiLv, S. W. (2010). Determinants and performance index of foreign direct investment in China's agriculture. Determinants and performance index of foreign direct investment in China's agriculture.

[9] Rashid, I. M. A., \&Razak, N. A. A. (2016).Determinants of Foreign Direct Investment (FDI) in Agriculture Sector Based on Selected High-income Developing Economies in OIC Countries: An Empirical Study on the Provincial Panel Data by Using Stata, 2003-2012.Procedia Economics and Finance, 39, 328-334.

[10] Rashid, I. M. A., \&Razak, N. A. A. (2017). Economic Determinants of Foreign Direct Investment (Fdi) in Agriculture Sector Based on Selected Developing OIC Countries: An Empirical Study on the Provincial Panel Data by Using Stata, 20032012. JurnalIntelek, 12(1).

[11] Somasekar, J. \& Sharma, A. \& Reddy, N. \& Reddy, Y..(2020). IMAGE ANALYSIS FOR AUTOMATIC ENUMERATION OF RBC INFECTED WITH PLASMODIUM PARASITES-IMPLICATIONS FOR MALARIA DIAGNOSIS.Advances in Mathematics: Scientific Journal. 9. 1221-1230. 10.37418/amsj.9.3.48.

[12] A. SHARMA1 AND J. SOMASEKAR"Contrast Image Construction Technique for Medical Imaging" published in Advances in Mathematics: Scientific Journal (Adv. Math., Sci. J.) vol-9-no-6-2020 (pp 3325-3329)

[13] RohiniGoel, Avinash Sharma, and Rajiv Kapoor, "Object Recognition Using Deep Learning" published in Journal of Computational and Theoretical NanoscienceVol. 16, 4044-4052, 2019

[14] Santosh, Mamta\& Sharma, Avinash.(2019). A Proposed Framework for Emotion Recognition Using Canberra Distance Classifier.Journal of Computational and Theoretical Nanoscience.16. 3778-3782. 10.1166/jctn.2019.8250.

[15] MamtaSantosh, Avinash Sharma, "Facial Expression Recognition using Fusion of LBP and HoG Features" published in International Journal of Innovative 
Technology and Exploring Engineering (IJITEE) ISSN: 2278-3075, Volume-8 Issue-8 June, 2019.

[16] Abdullah K.;Chandrakala A; Prabhishek S; Manoj D; Shilpi S; Kanika S; Neeraj K,(2020), "A Comparative Study on Shells in Linux: A Review", Materials Today: Proceedings, Elsevier, 2020. 